\title{
Arduino Based Automatic Power Factor Control
}

\author{
Md Abdullah Al Rakib *\$(iD), Sumaiya Nazmi*(iD), Md Hasan Imam** (D), Mohammad Nasir Uddin**(iD) \\ * Department of Electrical and Electronic Engineering, Faculty of Science \& Engineering, City University-Bangladesh, \\ Dhaka-1216

\begin{abstract}
**Department of Electrical and Electronic Engineering, Faculty of Science \& Engineering, American International University-
\end{abstract} \\ Bangladesh, Dhaka-1229
}

(alrakib108@gmail.com, hasan.imam@aiub.edu,drnasir@aiub.edu,kheya.naz@gmail.com)

†Corresponding Author; Md. Abdullah Al Rakib, Dhaka-1216, alrakib108@gmail.com

Received: 29.06.2021 Accepted:29.08.2021

\begin{abstract}
When the inductive load is brought into the industry, it is known that the power factor will drop. The electricity cost will be greater if the power factor is decreased. When the power factor drops in our system, the automated capacitor sets are activated, and the factor of power is restored with a predetermined level. The unique element of our research work is that an IoT (Internet of Things) technology was used to complete it. It will be capable to monitor and operate the research work from any place on the Internet, in addition to monitoring from the research work display. As a programming device, it has been utilized an Arduino Uno Microcontroller. The PF may be improved to increase current-carrying capacity, enhance voltage to equipment, minimize power losses, and cut electric costs. Reactive current generators are PF correction capacitors. We contribute to increasing the power factor by helping to balance the nonworking power used by inductive loads. In this article, the power factor of a load is measured using an Arduino Uno microcontroller, in which the necessary capacitors are then triggered to compensate for reactive power and put the factor of power closer near unity.
\end{abstract}

Keywords Arduino Uno, power factor, active power, reactive power, voltage converter, relay module.

\section{Introduction}

Industrial and commercial firms competing in today's competitive marketplaces place a premium on electrical energy efficiency. One of the primary problems that companies strive to reconcile with vitality effectiveness for both reasonable and eco-friendly reasons is the optimal utilization of plants and equipment. Reduced energy usage is becoming increasingly important as society becomes more mindful of its environmental control, and it is a goal that everyone can achieve. Power factor adjustments are optimized by the use of measurements such as electricity usage, resulting in lower energy consumption and lower $\mathrm{CO} 2$ greenhouse gas emissions. Its use, however, is contingent on the dimension of the fixing and the range to which the factor of power adjustment is required. By keeping the system reliable, automatic power factor adjustment procedures may be used in power systems, industrial units, and even households. Therefore, the system develops more steadily and the structure's and apparatus' efficiency improves [1].

Capacitor sets for 1 phase use in industry and household solicitations were developed in response to saving power and management of reactive power issues. The goal of the research work is to build a microprocessor-based control system to improve and advance the functioning of 1 phase capacitor sets.
The capacitor set will be controlled by the control unit. The current converter is familiar to measure the load current for the sampler, and it plays a significant part in this process. The unique element of our research work is that we used IoT (Internet of Things) technology to complete it. We will be capable to monitor and operate the research work from anywhere over the Internet, in addition to monitoring from the research work display. This microcontroller control unit's intelligent control guarantees even capacitor step use reduces the amount of switching tasks and improves power factor correction [2].

The major goal of this scheme has to develop a spontaneous power factor control system for the goal of making a smart system that will allow us to reap many advantages from a single undertaking. (a) The power quality is improved by continually monitoring the load power factor. (b) Construct an Arduino Uno type correction device for raising the system power factors to the target value close to 0.95. (c) To diminish the penalty. (d) To detect the anomaly before it occurs. (e) Using (IoT) concept, monitor the system's parameters using an online program. (f) A system for checking and adjusting IoT devices.

The active power $(\mathrm{kW})$ is required for accomplishing the real job, and the reactive power (KVAR) is required for 
sustaining the magnetic pitch. The reactive power is required for the apparatus to functioning, then by causing the current being out of phase with the input signal, creates a negative load on the source (voltage leads current). When dormant motors are used below that peak charge, such as when a surface grinder is used to build a light cutting or a rotary out was merely rotated, or empty compressor for air, a low power factor might occur. Poor power factor losses are produced by reactive current rolling in the method, which may be reduced utilizing PFC [3]. It has been noticed that power is extremely valuable in the current technology revolution. Industrialization largely increases inductive loading, which reduces the factor of power and reduces the efficiency of the energy scheme. This automated power factor adjustment device is a highly important tool for increasing the efficiency of active power transmission. The power factor falls when a consumer attaches an inductive load; when this power factor goes down 0.97 (lag), the electric company will charge the consumer a penalty. As a result, it's critical to keep the power factor below a certain threshold. The spontaneous power factor improvement gadget calculates the compensation required switch on various capacitor banks by reading the factor of power at line current and line voltage.

Because this least current is required to transfer a given quantity of real power, the optimum number for unity factor of load power, which is a clean resistive load. Real-world loads differ after this best. Because electrical motor loads are phase lagging (inductive), capacitor sets are required to compensate for this inductance. Inductors are occasionally used to adjust the factor of power when it is to lead owing to capacitive load. Even if reactive power is flowing backward and forward among every ac sequence, the inductors are claimed for consuming it and, capacitors remain believed to supply it in the electric sector [4].

\section{Literature Review}

A.R.Danila Shirly and her team explore the various power factor correction techniques used in industrial loads and a new topology is proposed to automatically improve the power factor by injecting the reactive power produced by the capacitor bank connected with a load. They used PWM inverter and dynamic compensation for their work and did not give the proper circuit diagram of their research work [5]. K. Naresh and his team present a model about the modest and cost-effective plan of a spontaneous power factor correction (SPFC) scheme for 1 phase native loads. They used Optocouplers and Capacitive Load for their work which is different from our work [6]. M. SIVA SAI PRASAD and his team primarily advocated employing power factor correction via a multitude of shunt capacitors to reduce loss of power in the industry. They reduced the cost of their work but cost analysis had not mentioned [7]. Nanda.P1, Sunil Rathod reviewed the disadvantages of lagging power factor, advantages of power factor improvement, working methodology, and its future scope. In their paper, the results part had not shown clearly but we have [8]. Balamurugan K, Gowsika M proposed a model for power factor adjustment and they used SEPIC converter and boost converter [9].
In this paper, we have planned a low price hardware and software model that has been used a simple Arduino Uno, relay module, ESP8266 wifi module, simple blynk server and app, and some basic equipment, and our further improvement will be to take the power factor value greater than the 0.95 .

\section{Design of Power Factor Control}

Spontaneous Power Factor Revealing and Correction works upon the principle of continuously checking the system power factors and initiating necessary corrections if the power factor falls below the predetermined value. Instrument transformers linked in the circuit are used to sample the voltage and current signals. These instrument transformers provide stepped-down current and voltage values that are proportionate with the diagram of voltage and current. These recorded analog indicators are transformed to appropriate digital signs by the zero overpass detection, which changes state at every zero-crossing point of the voltage and current measurements. [10].

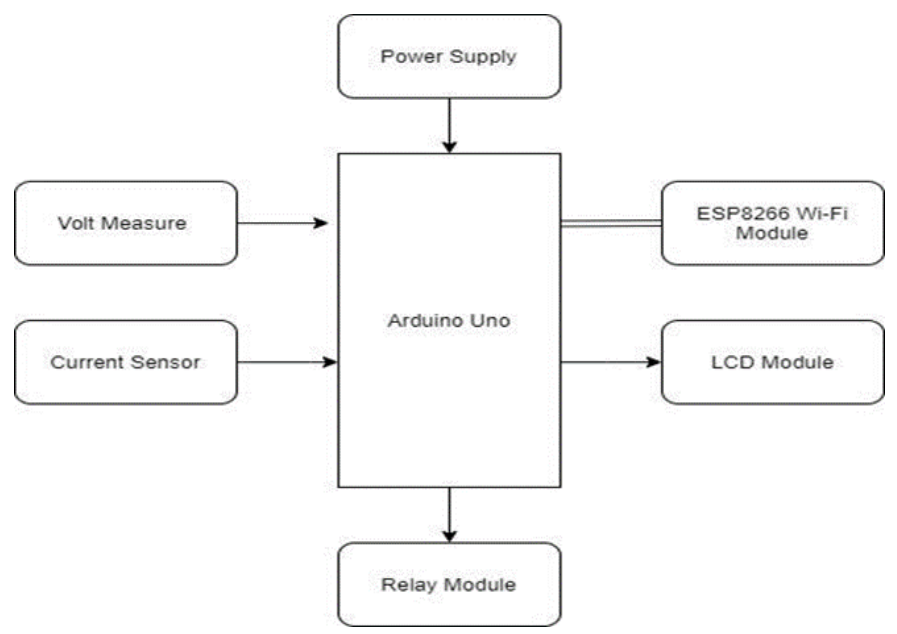

Fig. 1. Functional block diagram of the prototype.

The Arduino Uno development board, sensor, and Wi-Fi module were utilized in this suggested system. The system in this research work is entirely powered by electricity. The major goal of IoT-based Automatic Power Factor Control. The current sensor, voltage sensing system, LCD, relay module, and Wi-Fi module are all shown in the block diagram above. The microcontroller monitors the sensor's output and sends a signal to the IoT system circuit, which controls the applications.

In figure 2, a circuit has been designed with Arduino Uno. To measure the line voltage here, the voltage was reduced and worked with some basic equipment like register, current sensor to measure current, a capacitor to improve the power factor system. A LCD has been attached for monitoring the output data and also used a Wi-Fi module for controlling and monitoring over the internet. By using relays the loads will be controlled and Arduino Uno had used as programming device [11]. 
INTERNATIONAL JOURNAL Of SMART GRID

Md. A. Al Rakip et al., Vol.5, No.3, September, 2021

All details of equipment in research work are given. Arduino Is open microcontroller board is equipped with Sets ATmega328P microprocessor and created by Arduino.

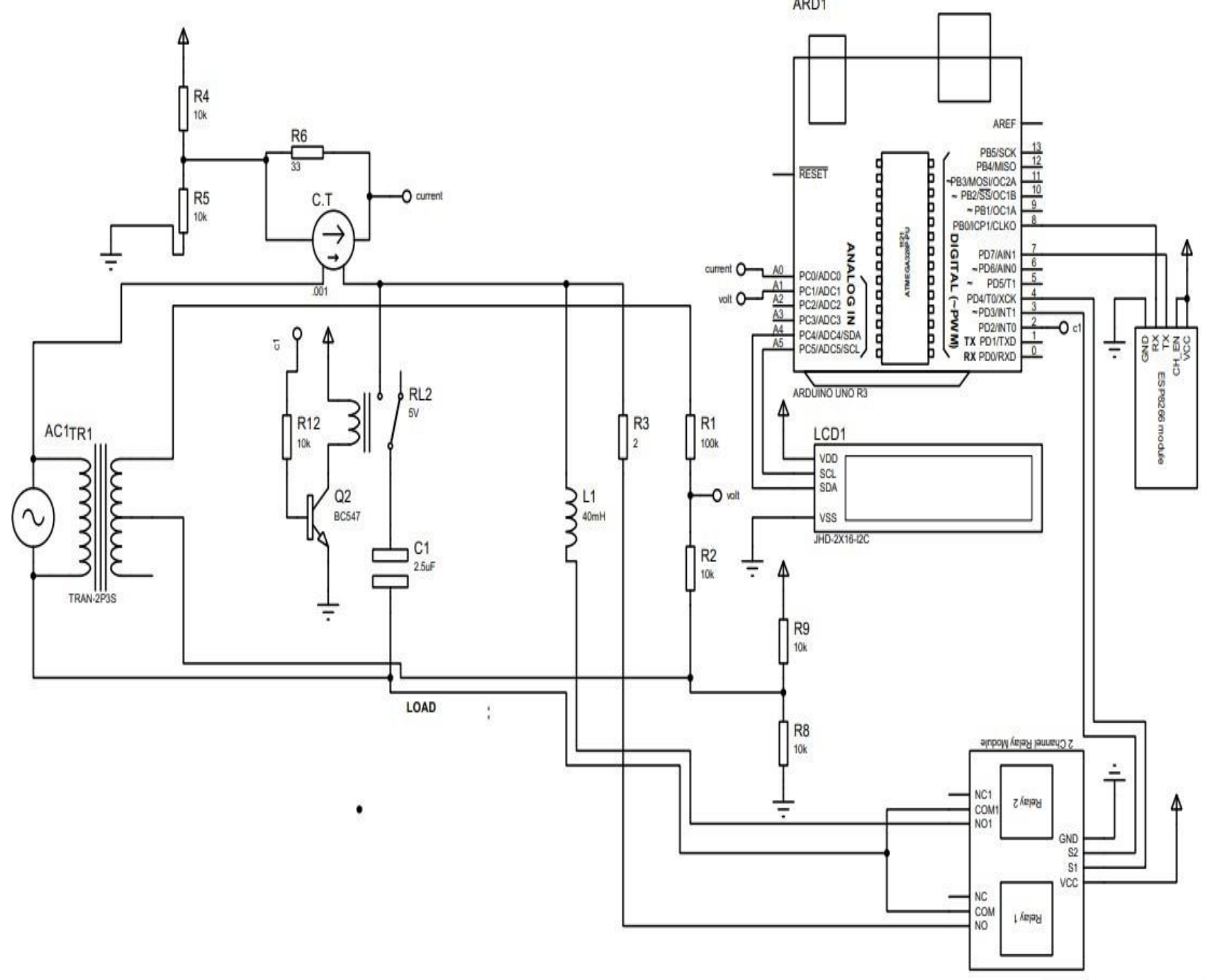

Fig. 2. Circuit of the arduino based power factor correction. 


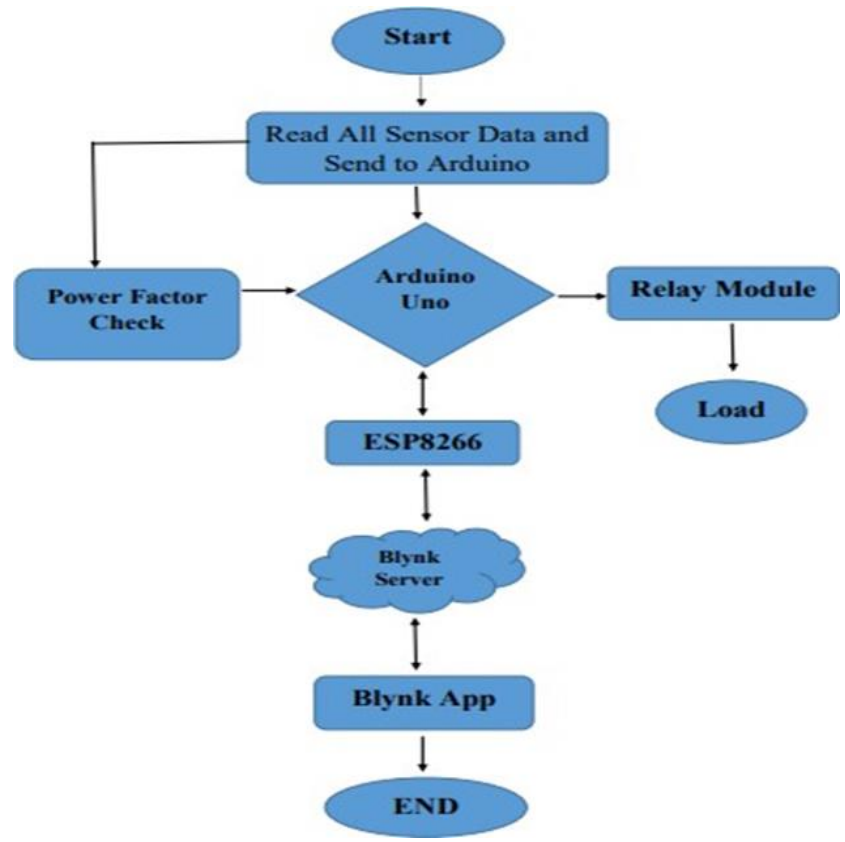

Fig. 3. Flow chart of the entire system.

The LM2596 voltage converter is a set of uniform integrated circuits that perform all of the active operations for a step-down switching controller accomplished of motivating a 3-A load by good line and load control. Stable output voltages of $5 \mathrm{~V}, 3.2 \mathrm{~V}$ and $12 \mathrm{~V}$, as well as a modifiable output version, are offered. The ESP8266 is a cheap Wi-Fi chip that includes a full IP stack as well as a microcontroller. A relay was also utilized, which is a device that is powered by electricity.

It has a control system as well as a controlled system (also known as an input circuit) (also called an output circuit). A current sensor chip with a rating of ACS712ELC-30A was also utilized to determine the output current value. Because there is no test current, the output voltage is $\frac{V c c}{2}$. A capacitor set is a collection of similar or non-identical capacitors that are linked in series or parallel with each other. These capacitors assemblies are generally employed for rectification or counter unwanted features of an alternating current electrical power supply, like the factor of power lagging or phase-shifting [1219].

\section{Software Development of This System}

One of the best significant components of the MCU-based Single phase induction motor driving, regulating, and protection system is the software. The algorithm is based on a variety of circumstances and measurements. The software is in charge of the entire system's operation. The code is written in the $\mathrm{C}$ programming language. The Arduino software installation and setup instructions are provided below. Arduino software was downloaded and installed on the computer from www. arduino.cc (This was NOT connected to the PC) [20-23].

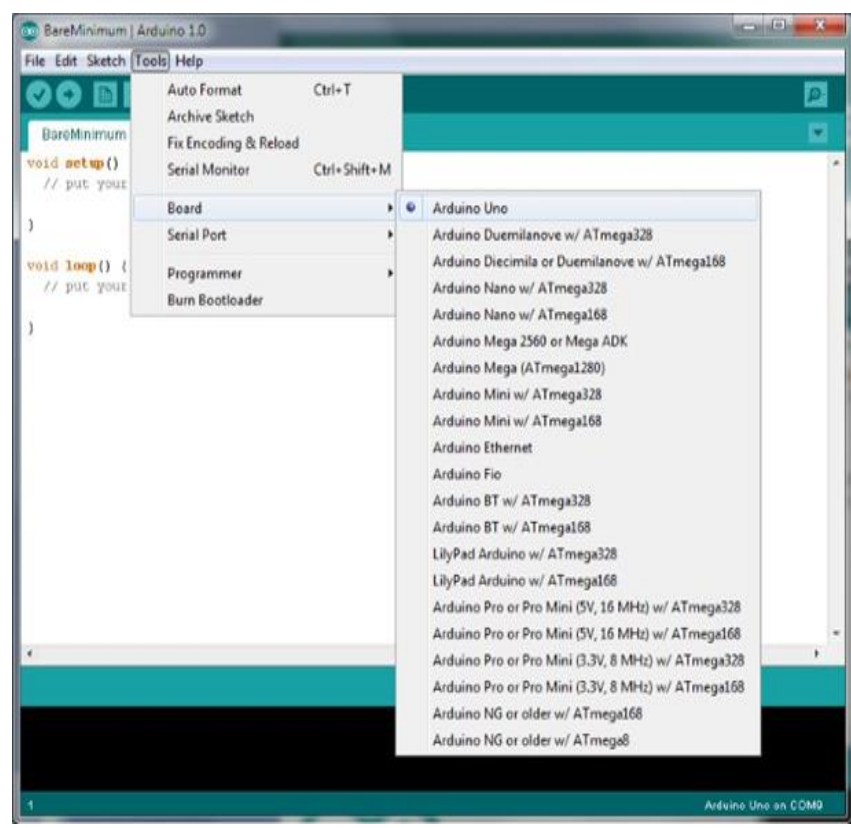

Fig. 4. The complete prototype of the proposed model

The Arduino was not linked to the computer at the time. If we now select "Port" from the "Tool" drop-down menu, we will find one or more ports listed (COM1/ COM2/ COM3...). The number of displayed ports is independent of the number of USB ports on the machine. We'll discover another port after the board is linked to the PC.

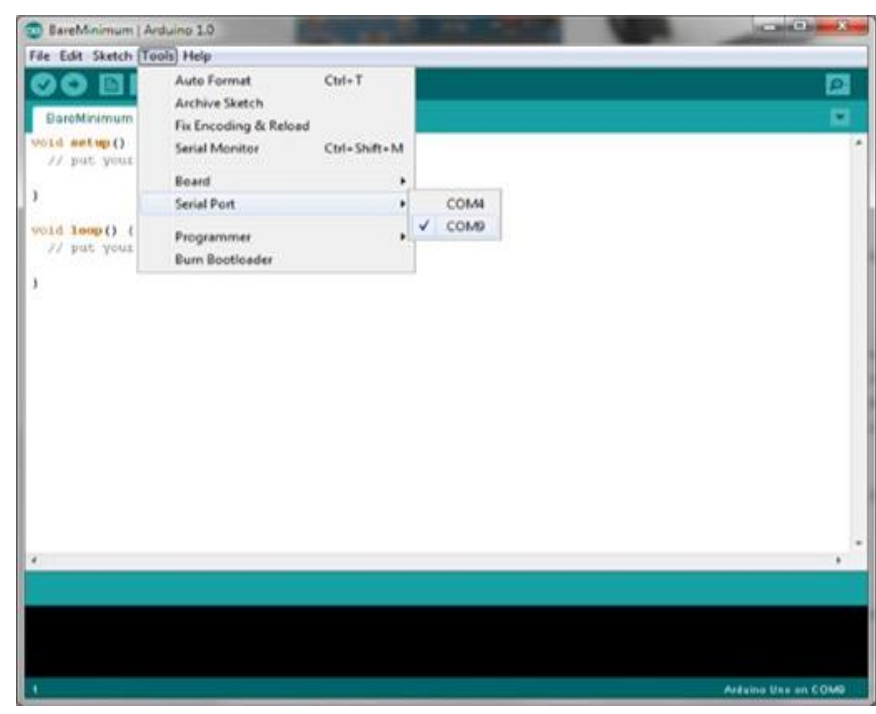

Fig. 5. Program installation process -2 . 


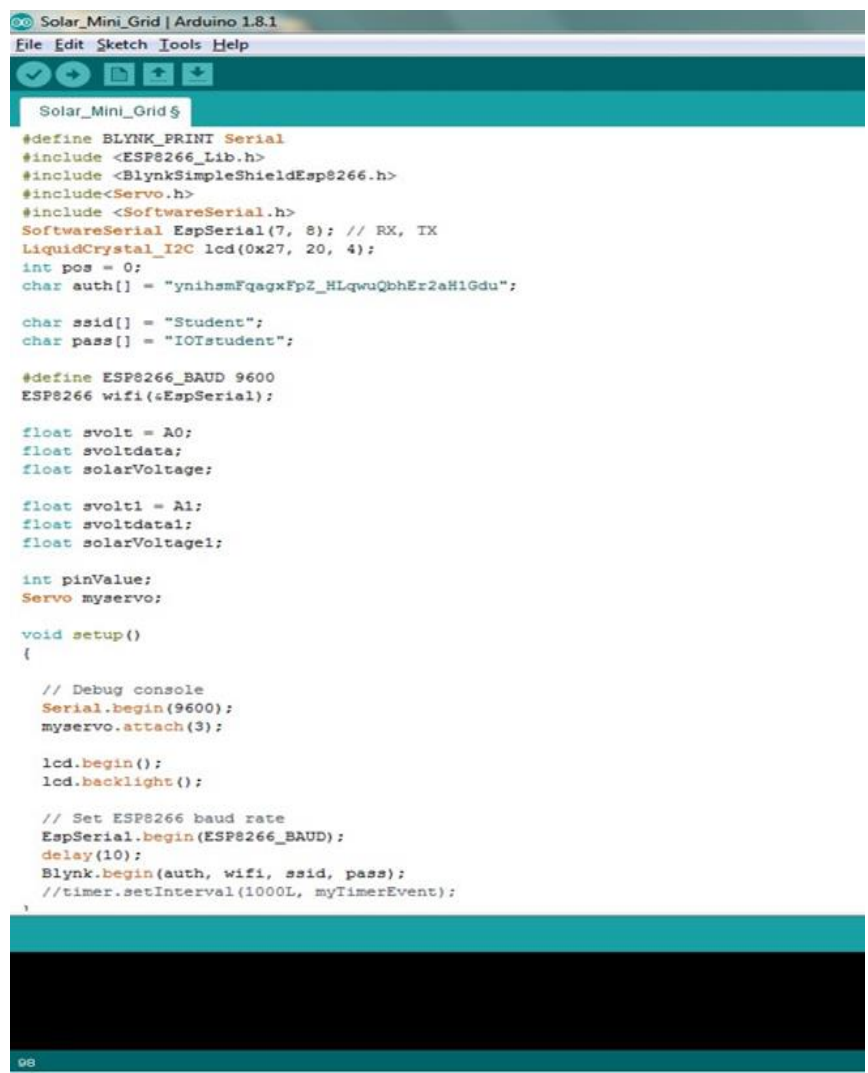

Fig. 6. Program installation process -3 .

Proteus 7.0, a Simulated Arrangement Modeling that integrates circuit model, active apparatuses, and microprocessor copies to co-simulate entire microcontrollerbased designs, was familiar to simulate the circuit [24]. This application allows users to relate with the scheme via onscreen indications, LCDs, as well as controls and keys if the PC is connected. Circuit Simulation, one of the primary apparatuses of Proteus 7.0, is a tool that combines a SPICE3f5 analog trainer with a digital simulator to allow users to use any SPICE model from any vendor [25-27].

The development cycle was separated into 4 phases:

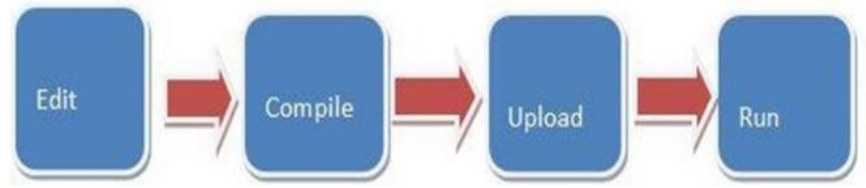

Fig. 7. Flowchart of the compiling process.

\section{Results and Output Observations}

When we give power to our research work, the research work will start, if Q enters through the entrance. The power factor will decrease only when the inductive load is turned on. Whenever the power factor in this system is reduced, the automatic capacitor bank will be connected and the power factor will be taken to the specified level. We can monitor it from the display on the research work and IoT system. We will be capable to monitor all the data of our research work such as Voltage, Current and Power Factor from one display. We can control the connected loads from anywhere through the internet and monitor the data.

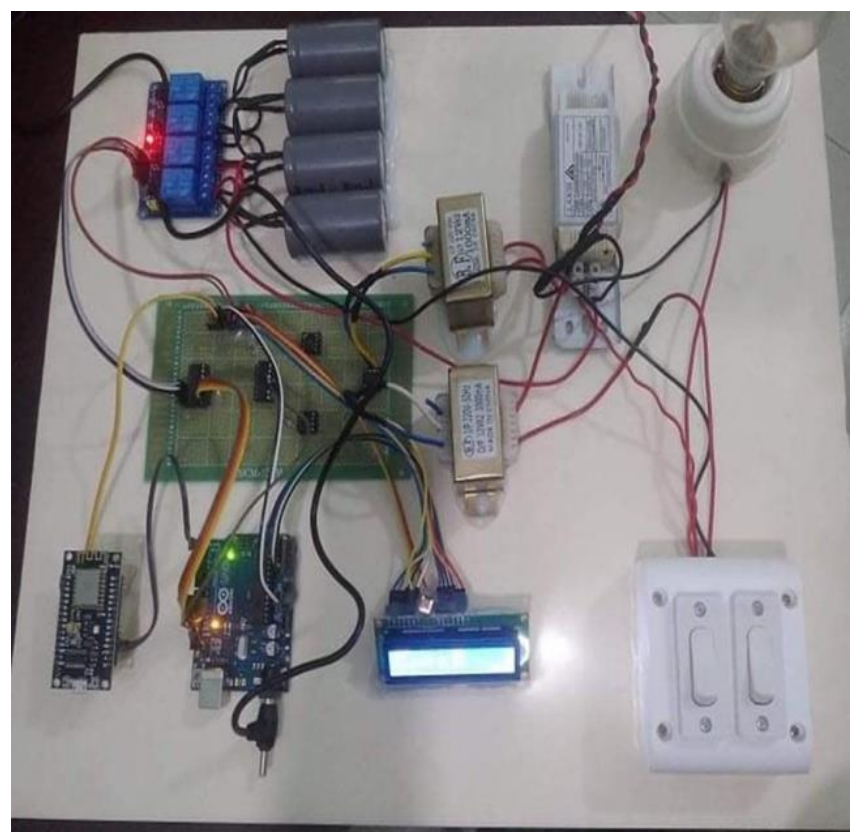

Fig. 8. Hardware Development of the System.

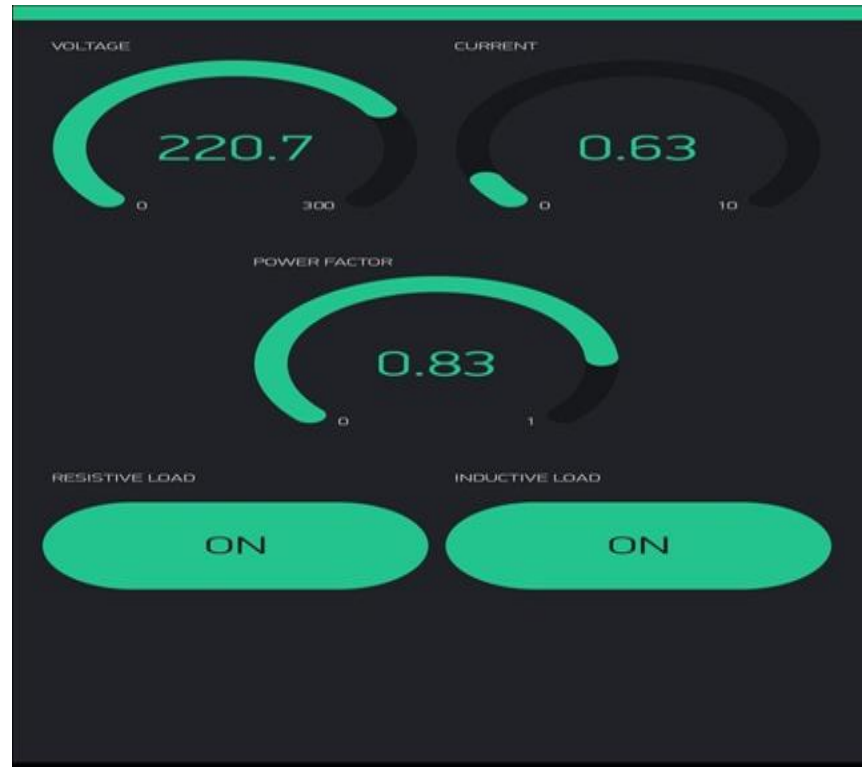

Fig. 9. Observation of output results.

In this work, we can control the power factor to 0.83 which is very much effective in the Power sector. We can control this power factor continuously by our work and reduce the voltage losses.

Table 1. When operated in IDMT over-voltage mode

\begin{tabular}{|c|l|c|c|c|}
\hline SL. & Components & Quantity & Unit Price & (Taka) \\
No. & Name & & & \\
\hline 1 & Arduino Uno & 1 & 460 & 460 \\
\hline
\end{tabular}




\begin{tabular}{|c|l|c|c|c|}
\hline 2 & $\begin{array}{c}\text { Buck } \\
\text { Converter }\end{array}$ & 1 & 110 & 110 \\
\hline 3 & WIFI Module & 1 & 290 & 290 \\
\hline 4 & Relay Module & 3 & 70 & 210 \\
\hline 5 & LCD Display & 1 & 450 & 450 \\
\hline 6 & Current Sensor & 1 & 250 & 250 \\
\hline 7 & $\begin{array}{c}\text { Power } \\
\text { Capacitor }\end{array}$ & 1 & 80 & 80 \\
\hline 8 & Adaptor & 1 & 450 & 450 \\
\hline 9 & Others & & 500 \\
\hline Total Cost & & & \\
\hline
\end{tabular}

\section{Conclusion}

Power factor adjustment plays a key part in conserving energy in this climate to conserve more energy for the future. As a result, this article describes a system that continually analyzes several aspects of an induction motor and updates these data on a webpage utilizing IoT. We manage the power factor to 0.85 which is remarkable here and if a fault happens, the device will send an alarm message to the person who is responsible for the problem, and an electrical relay is activated. Because the power factor will decrease as the inductive load increases, this system features a power factor enhancement method by swapping the capacitor banks. The major goal is to create Automatic Power Factor Adjustment (APFC) Units for load changes that can monitor an induction motor's energy usage and increase its power factor continuously. It will aid in the reduction of penalties associated with poor power factors and services in the preservation of induction motors, as well as the identification of issues before failure. The power factor component improved the power factor from 0.76 to 0.97 under the testing load conditions. The mean power consumption savings were about $1.7 \%$ of the intended load, with a variety of loading conditions. Only with the precise amount of power factor correction, the system capacity is freed when the current drawn is lowered. According to the economic study, the payback period would be about 9 months, with considerable energy cost reductions.

\section{References}

[1] A.R.D. Shirly, K.Vijayaragavan , R.V. Chander , M.Santhosh, M.P. Kumar. "Dynamic compensation of reactive power: comparitive analysis of power factor correction techniques, pp. 67-87."
[2] K. Naresh , T. Kumar , Md. Sameer , S. Reddy K. "Arduino-based auto power factor correction using Optocouplers and Capacitive Load Banks, pp. 172-176."

[3] M. S. S. PRASAD , P. K. KHAN , R. V.S. KUMAR , K. PANDARINADH , G. SRINIVAS. "Automated Power Factor Correction And Monitoring System."pp. 87-93 (2020).

[4] P. Nanda, S. Rathod , B. Halapeti, D. Poojari, G. Math , S. Jalageri, "Automatic Power Factor Correction Using ATmega328."

[5] K. Balamurugan, M. Gowsika, T. Monika, N. Naveen. "Power Factor Correction Using Sepic Dc-Dc Converter in Industrial Motor Drives." Ch.4, pp. 34-39.

[6] R. Dhameliya , K. Domadiya, P. Miyani , H. Savaliya , P. Jariwala. "Automatic power factor control using arduino uno." International Journal of Advance Engineering and Research Development (IJAERD) 4.4 (2017).

[7] P.P. Machado , T. P. Abud , M. Z. Fortes , B. S, M, C, Borba . "Power factor metering system using Arduino." 2017 IEEE Workshop on Power Electronics and Power Quality Applications (PEPQA). IEEE, 2017.

[8] M. B. Khan, M. Owais, "Automatic power factor correction unit." 2016 International Conference on Computing, Electronic and Electrical Engineering (ICE Cube). IEEE, 2016.

[9] N.H. Ishak, M.N. Zainodin, N.A. Salim, F.M.T. Tawi, A. H. Mohd Saod. "A design of an automatic single phase power factor controller by using Arduino uno Rev-3." Applied Mechanics and Materials. Vol. 785. Trans Tech Publications Ltd, 2015.

[10] W. Ali, H. Farooq, M. Jamil , A. Rehman, R. Taimoor, M. Ahmad . "Automatic Power Factor Correction for Single Phase Domestic Loads by Means of Arduino Based TRIAC Control of Capacitor Banks." 2018 2nd International Conference on Energy Conservation and Efficiency (ICECE). IEEE, 2018.

[11] Y. Kabir, Y. Mohammad Mohsin and M.M. Khan. "Automated power factor correction and energy monitoring system." 2017 Second International Conference on Electrical, Computer and Communication Technologies (ICECCT). IEEE, 2017.

[12] T. S. Gunawan, M. H. Anuar, M. Kartiwi, Z. Janin. "Development of Power Factor Meter using Arduino." 2018 IEEE 5th International Conference on Smart Instrumentation, Measurement and Application (ICSIMA). IEEE, 2018. 
[13] S.B. Jarad, V. D. Lohar, S. P. Choukate, S. D. Mangate. "Automatic Optimization and Control of Power Factor, Reactive Power and Reduction of THD for Linear and Nonlinear Load by Using Arduino UNO." 2018 Second International Conference on Inventive Communication and Computational Technologies (ICICCT). IEEE, 2018.

[14] M. M. Than, "Implementation of Power Factor Correction Using Solid State Switched Capacitors." IOSR J. Electr. Electron. Eng. 11.04 (2016): pp. 70-79.

[15] S. Mane, R. Sapat, P. Kor, J. Shelar, R.D. Kulkarni, J. Mundkar. "Microcontroller based Automatic Power Factor Correction System for Power Quality Improvement." 2020 International Conference for Emerging Technology (INCET). IEEE, 2020.

[16] G. W. Chugulu, F. Simba, S. Lujara. "Proposed Practical Communication Architecture for Automatic Fault Detection and Clearance in Secondary Distribution Power Network." International Journal of Smart GridijSmartGrid 4.4 (2020): 164-175.

[17] H. A. Illias, N. S. Ishak, N. A. M.N. Alam. "Awareness of Secondary School Students in Petaling Jaya Malaysia Towards Renewable Energy." International Journal of Renewable Energy Research (IJRER) 10.4 (2020): 16451654.

[18] G. Soufiane , F. Ouafia , A. Ahmed. "Solar Power Time Series Prediction Using Wavelet Analysis." International Journal of Renewable Energy Research (IJRER) 10.4 (2020): 1764-1773.

[19] Y. E. A. Eldahab , N. H. Saad, A. Zekry. "Enhancing the Energy Utilization of Hybrid Renewable Energy Systems." International Journal of Renewable Energy Research (IJRER) 10.4 (2020): 1974-1987.

[20] R. Meligy , M. Rady , A. E. Samahy, W. Mohamed , F. Paredes , F. Montagnino. "Simulation and control of linear
Fresnel reflector solar plant." Int. J. Renew. Energy Res 9.2 (2019): 804-812.

[21] M. S. Mahamud, M. A. A. Rakib , T. M. Faruqi, M. Haque, S. A. Rukaia, S. Nazmi. "Mouchak-An IoT Basted Smart Beekeeping System Using MQTT." 2019 4th International Conference on Robotics and Automation Engineering (ICRAE). IEEE, 2019.

[22] M.A.A. Rakib, M. T. Ali, M. S. Mahamud, T. M. Faruqi, S. A. Rukaia, M. Haque. "Energy Harvesting Technology from Human Motion." 2020 2nd International Conference on Advanced Information and Communication Technology (ICAICT). IEEE, 2020.

[23] M.H.K. Khan and M.A.A. Rakib. "Implementation of Inverse Define Minimum Time Under and Over Voltage Relay." International Journal of Smart Grid-ijSmartGrid 5.2 (2021): 88-93.

[24] M. H. K. Khan, S. Uddin, M. M. Rahman and M. A.A. Rakib. "Pure Sine Wave Inverter Design for Street Light Emergency Backup System."

[25] M.A. A. Rakib, M. S. Rana, M. M. Rahman and F. I. Abbas. "Dry and Wet Waste Segregation and Management System." European Journal of Engineering and Technology Research 6.5 (2021): 129-133.

[26] M.A.A. Rakib, S. Ahmad, T. M. Faruqi, M. Haque, S. A. Rukaia , and S. Nazmi. "Design and Simulation-Based Parametric Studies of a Compact Ultra-Wide Band Antenna for Wireless Capsule Endoscopy System at Inside Body Environment." International Journal of Electrical and Electronic Engineering \& Telecommunications (2021).

[27] S. Ahmad, R. R. Hasan, R. Hasan, M.A.A. Rakib, M. A. Hasan, M. Zubayar. "A low SAR in-body antenna for wireless monitoring purpose of pacemaker system." 2019 4th International Conference on Electrical Information and Communication Technology (EICT). IEEE, 2019. 